\title{
Improved Diagnosis of Boiler Feed Pumps in a Thermal Power Plant
}

\author{
R.Zarrouk, M. El Amrani, H. El Maati, H. Santillan-Ortiz
}

\begin{abstract}
In thermal power plants, the boiler feed pumps are classified as vital machines. Therefore, the lack of its availability leads immediately to a loss of electricity production. They can also be the source of serious incidents or accidents that directly threaten the operational safety of the machine, as well as the safety of personnel. The inspection is a very effective solution to reduce the possibility of an accident. The vibration analysis can specifically detect with opportunity the possible mechanical, hydraulic and electrical defects that probably exist in motor pump. This document presents different techniques of vibration analysis, which were applied in different pumps to make an effective diagnosis.
\end{abstract}

Keywords : Control and diagnosis of motor pumps, spectral analysis, envelope analysis, time-frequency analysis, scalogram.

\section{INTRODUCTION}

To satisfy the growing consumption of electricity, it is necessary to guarantee its production efficiently and continuously. In order to achieve this objective, the strategic facilities of the production units have to be reliable and must be maintained in optimum conditions, In particular the turbo units and the feed pumps that constitute the main facilities of the thermal power plant.

The maintenance of these strategic facilities has the following objectives: firstly the security, which guarantees the safe operation of machinery and the integrity of people. Secondly the economic factor, which limits untimely downtime. It should be borne in mind that the Jerrada power plant in Morocco, despite the redundancy of the pumps, has caused large losses in production in the last ten years, synonymous with a loss of several thousand dollars in revenue [1-3].

Of all the techniques of conditional maintenance, the vibration analysis is the most appropriate technique for rotary machines [4-7]. Not only it informs about the state of the machine health, but also it can detect the defective part and even the type of defect. In fact, the vibratory signals

Revised Manuscript Received on December 30, 2019.

* Correspondence Author

R.Zarrouk*, Department Of Electronique And System, University Mohammed I, Oujda, Morocco, Zarroukredouan1@Gmail.Com.

M. El Amrani, Department Of Electronique And System, University Mohammed I, Oujda, Morocco, Mostafa_Elamrani@Yahoo.Fr

H. EL Maati, Department In Technological, University Mohammed I, National School Of Applied Science, Oujda, Morocco, Elmaat@Onee.Ma.

H. Santillan-Ortiz, Department In Technological University Of Mexico. Ecatepec, Estado De Mexico, Mexico, Hortensia@Gmail.Com.

(C) The Authors. Published by Blue Eyes Intelligence Engineering and Sciences Publication (BEIESP). This is an open access article under the CC BY-NC-ND license (http://creativecommons.org/licenses/by-nc-nd/4.0/) generated by these machines contain valuable information about their correct operation. The processing of these signals can provide an accurate diagnosis of the machines. Several

analysis techniques depend on the used type of signal processing [8]. These treatments are often complementary and necessary for a good diagnosis. Three types of analysis were applied to our boiler feed pumps: frequency analysis, envelope analysis and time-frequency analysis.

\section{TECHNIQUES OF ROTATING MACHINES VIBRATORY ANALYSIS}

The vibration analysis is based on the evaluation of the measured vibratory signal with the help of an accelerometer placed near the organ to be monitored. There is a multitude of time, frequency and frequency methods. These methods are complementary for a better diagnosis. In this paragraph we mentioned the principle of the most common methods used to control boiler feed pumps.

- Spectral analysis [8] whose principle is to measure the time signal $\mathrm{x}(\mathrm{t})$, and then calculate its spectrum $\mathrm{X}(\mathrm{F})$. This calculation can be done using the Fourier transform; but since vibratory signals are generally random, it is preferable to use the Spectral Power Density (SPD) representing the Fourier transform of the autocorrelation of the measured signal $\mathrm{x}(\mathrm{t})$ [9], that is :

$$
\operatorname{SPD}(\mathrm{F})=|\mathrm{FT}(\mathrm{Rx}(\mathrm{t}))|
$$

Where FT is the Transform Fourier and Rx (t) the autocorrelation of the signal $\mathrm{x}(\mathrm{t})$, defined by equation (2):

$$
\operatorname{Rx}(t)=\lim _{T \rightarrow \infty} \int_{-\infty}^{\infty} x(t) \cdot x(t+\tau) d x
$$

Knowing that most of the anomalies affecting the rotating machines (imbalance, misalignment, fixation, and electromagnetic defects) generate to vibrations whose frequencies correspond to the appearance frequencies of the forces which induce these anomalies; the comparison of the measured spectrum with the spectral signatures of these defects reveals their presence.

- Phase analysis [8] is a technique complementary to spectral analysis. It allows to separate the defects resulting from the rotation forces from those coming from the directional forces. The principle consists of simultaneously measuring two signals using two sensors placed perpendicularly on the same level.

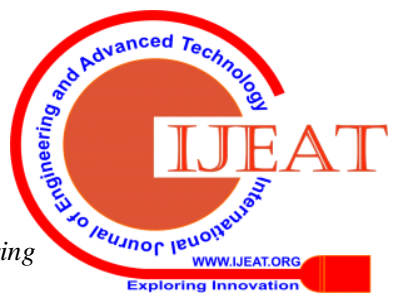




\section{Improved Diagnosis of Boiler Feed Pumps in a Thermal Power Plant}

Then, we calculate the frequency signal of each measurement, and we deduced the phase shift at the rotation frequency of the shaft. If this phase shift is close to $90^{\circ}$, so the defect is linked to a rotation force. If it is close to $0^{\circ}$ or $180^{\circ}$, then the defect is related to a directional effort.

It is a widely used technique to separate the imbalance defect from the fixation fault that has the same spectral signature.

- Envelope analysis is a technique that highlights bearing failures [10-11], gear failures [12] and electric motors failures [13-14].

Although this modulation produces, in the spectrum, lateral bands around the main frequencies of the system (meshing frequency, notch frequency, etc.). These bands are very little visible due to their low energies; it requires amplitude demodulation to highlight them.

The envelope analysis, consists to measure the filtered time signal $\mathrm{x}(\mathrm{t}$ ) around the carrier Fp (the carrier Fp is the notch frequency in the case of electric motors the meshing frequency in the case of the gears and the resonance frequency in the case of bearings), and then to calculate the relative analytical signal $\mathrm{z}(\mathrm{t})$ at the filtered signal $x(t)$, it should be referred to as Equation 3:

$$
z(t)=X(t)+\left(X(t) * \frac{j}{\pi t}\right)
$$

By definition $\mathrm{x}(\mathrm{t}) * \frac{1}{\pi \mathrm{t}}$ is the Hilbert Transform (HT) of $x(t)$. Equation (3) can be rewritten as :

$$
z(t)=X(t)-j * H T(X(t))
$$

The envelope e (t) of the signal $x(t)$ is defined by the module of the analytic signal $\mathrm{z}(\mathrm{t})$ :

$$
\boldsymbol{e}(\mathrm{t})=|z(t)|=\sqrt{X^{2}(t)+\mathrm{HT}^{2}(X(t))}
$$

The spectrum of the envelope would contain modulation lines whose position reveals the type of defect that gives rise to this modulation.

- The Time-frequency analysis is an analysis that allows to characterize the frequency content of a signal as a function of time. Several types of time frequency representations are proposed [15], but it is the wavelet transform that gives the best results [16-17].This transformation consists in decomposing the signal that will be studied based on elementary functions called wavelets $\psi_{\mathrm{a}, \mathrm{b}}(t)=\psi\left(\frac{t-b}{a}\right)$, time function $\mathrm{b}$ and frequency 1/a. The coefficients $\mathrm{C}$ (a, $\mathrm{b})$, obtained by decomposing the signal $\mathrm{x}(\mathrm{t})$ in the family $\psi_{a, b}(t)$, are given by Equation (6):

$$
C(\mathrm{a}, \mathrm{b})=\frac{1}{\sqrt{|\mathrm{a}|}} \int_{\mathrm{R}} \mathrm{x}(\mathrm{t}) \psi_{\mathrm{a}, \mathrm{b}}(\mathrm{t}) \mathrm{dt}
$$

The choice of mother wavelet depends, among others, on the type of the signal to study and the field of application. In this study, we chosed the Morlet wavelet [18], defined by Equation (7):

$$
\psi(t)=e^{-j \pi n \frac{t}{T}} e^{\frac{-t^{2}}{2 T^{2}}}
$$

Where $\mathrm{T}$ is the duration of the signal $\mathrm{x}(\mathrm{t})$ and $\mathrm{n}$ is the product of the center frequency Fo by $T$, then $n=F_{0}$. $T$. From this decomposition, we have created the Scalogram Scal (a, b) defined as the square of the wavelet transform $\mathrm{C}$ (a, b), that

Is:

$$
\operatorname{Scal}(\mathrm{a}, \mathrm{b})=|\mathrm{C}(\mathrm{a}, \mathrm{b})|^{2}
$$

The scalogram, defined by the "Equation (8)", is used in vibrational analysis to highlight amplitude modulation and frequency modulation [19].

In effect, the amplitude modulation is reflected in the scalogram by the appearance of a series of energy "blocks" equidistant and parallel to the time axis; while the frequency modulation gives rise to blocks distributed non-linearly according to the time axis and the frequency axis.

\section{DESCRIPTION OF THE BOILER FEED PUMP}

The motor pump unit of our thermal power plant consists of (Fig. 1 and Fig. 2):

- A synchronous electric motor of type ATD 2000 that rotates at a frequency of rotation $\mathrm{Fr}=50 \mathrm{~Hz}$. The number of notches of the rotor is 38 , which gives a notch frequency $F_{n}=1900 \mathrm{~Hz}$.

- Tow Fans installed on the motor shaft; its role is to provide sufficient cooling air. The number of blades for each fan is 8 which gives pass frequency of blades: $F_{b}=$ $400 \mathrm{~Hz}$.

- A rigid coupling that connects the electric motor to the pump.

- A barrel-type pump coupled to the electric motor. It is a centrifugal, multicellular and horizontal pump, ten stages and operates at a speed of 3000rpm, a rotation frequency of $50 \mathrm{~Hz}$. Each stage contains 9 blades, that is, a blade frequency $\mathrm{F}_{\mathrm{a}}=450 \mathrm{~Hz}$.

- A lubrication pump at the end of the shaft.

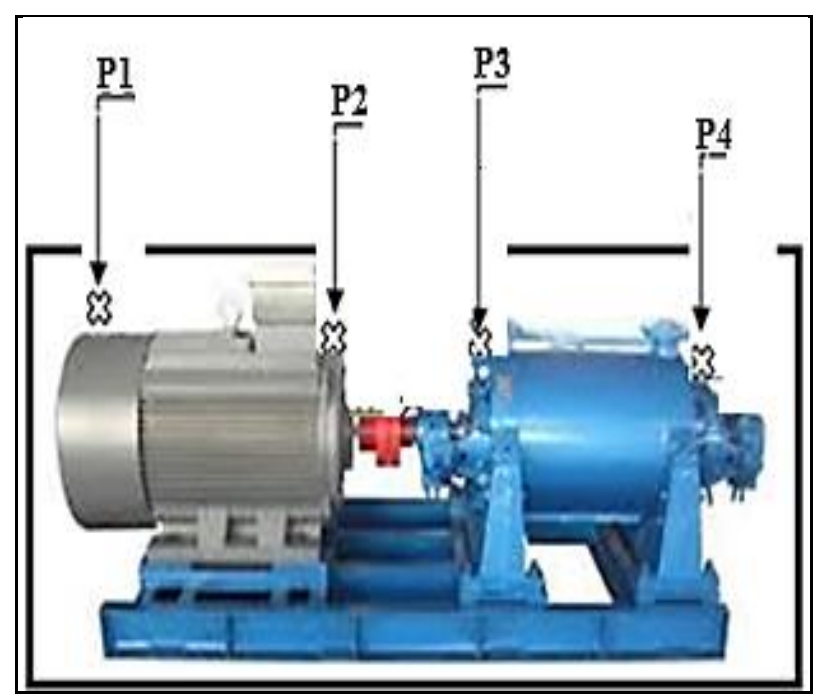

Fig. 1. Boiler feed pump diagram 


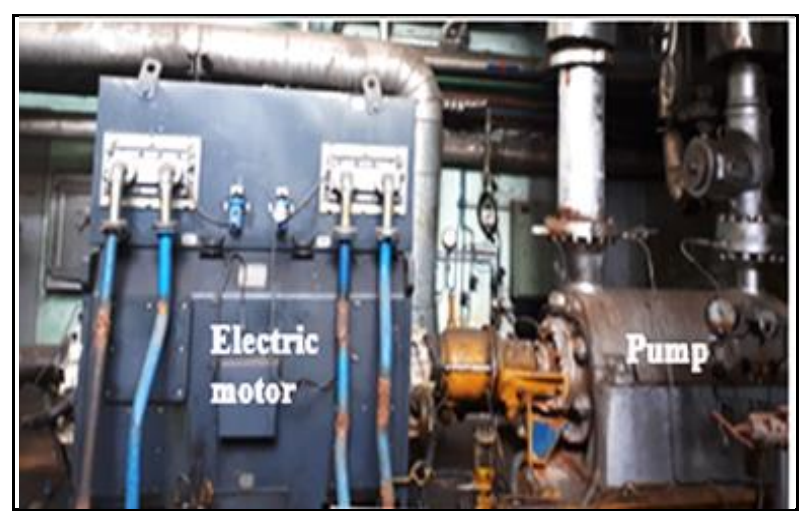

Fig. 2. Photo of Boiler feed pump Thermal Power plant

\section{VIBRATION ANALYSIS OF THE BOILER FEED PUMP}

Four measuring points were chosen for the control of the boiler feed pump: P1, P2, P3 and P4. In each of these points, a global analysis was taken. Measured RMS levels indicated that the pump was in poor condition.

Subsequently, frequency analysis, envelope analysis, frequency analysis and time for diagnosis were applied.

At point $\mathrm{P} 1$, the signals in the horizontal radial, vertical radial and axial directions in the frequency band $[0-2.5 \mathrm{KHz}]$ were measured with a line number NL $=800$ to verify the faults occurring at low and frequencies stockings such as imbalance, play, friction, shaft curvature, motor fixing, fan failures, etc.

Envelope detection was also performed around the notch frequency of the $\mathrm{Fn}=1900 \mathrm{~Hz}$ motor to control:

- Stator faults [8] such as centering fault, ovalization of the stator body, winding fault, phase imbalance, turns or leaves that are shorted or loose.

- Rotor faults [8] stories such as eccentricity of dynamic space, broken or cracked bars, leaves or shorted.

At point $\mathrm{P} 2$, the same measurements were taken as at point P1 to control the same defects mentioned above in addition to the misalignment between motor and pump.

At point P3, the signals in the horizontal radial, vertical radial and axial directions in the frequency band $[0-2 \mathrm{KHz}]$ were measured with a line number NL $=800$ to verify the faults related to the pump and to the coupling.

At point $\mathrm{P} 4$, the same measurements were taken as at point P3 to verify the same defects as well as the misalignment between the main pump and the lubrication pump.

\section{RESULT AND DISCUSSION}

During the control of the boiler feed pump, the acquisition of the signals was carried out by the Vibxpert system while the software V_System [20] ensured visualization and signal processing.

At point P2, the spectrum measured in the horizontal radial direction is visualized in Fig. 3.

The $50 \mathrm{~Hz}, 100 \mathrm{~Hz}, 150 \mathrm{~Hz}$ and $200 \mathrm{~Hz}$ lines have a large amplitude among the probable defects are imbalance and fixation. To eliminate this indeterminacy, a phase analysis was carried out. The phase shift measured at the rotation frequency is about $90^{\circ}$, which shows the existence of an imbalance.

The $100 \mathrm{~Hz}$ line is preponderant: the faults generated by this line are the parallel misalignment or variation of the stator current gap. For an exact determination of the defect, the frequency of the $\mathrm{Fn}=1900 \mathrm{~Hz}$ slot was extended (Fig. 4).

The small lines are present around the notch frequency that indicate the presence of the modulation phenomenon.

An envelope detection around Fe was then carried out.

The spectrum of the obtained envelope is visualized in Fig. 5, in which a dominant line at $100 \mathrm{~Hz}$ and a line at $50 \mathrm{~Hz}$ are seen, indicating the presence of a stator defect and a rotor defect of the dynamic space eccentricity type.

Since the amplitude of the $100 \mathrm{~Hz}$ line is much greater than that of the $50 \mathrm{~Hz}$ line, the stator defect is therefore more advanced than the rotor defect.

It should also be taken into account that in Figure4, the peak at $1850 \mathrm{~Hz}$ is greater than the peak at $1950 \mathrm{~Hz}$, so the band on the left side is larger than the right and consequently frequency modulation induced the modulation of the amplitude.

To highlight this frequency modulation it was calculated to then represent the scalogram of the signal measured in P2, in Fig. 6.

The shape of the scalogram shows the presence of a frequency modulation. The modulation frequency is equal to $50 \mathrm{~Hz}$, it is likely to be a crack in the rotor shaft.

At point $\mathrm{P} 4$, the spectrum measured in the horizontal radial direction is shown in Fig. 7. The occurrence of a resonance located after the frequency of $100 \mathrm{~Hz}$ is observed, that is, twice the rotation frequency of the axis; and other resonances located after the frequency of passage of the vanes of the pump $F_{a}=450 \mathrm{~Hz}$ and their harmonics. This is the spectral signature of a cavitation defect [21].

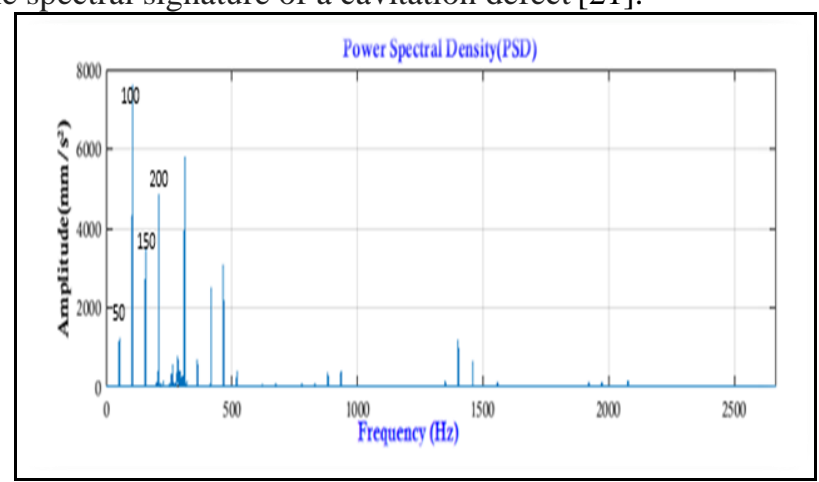

Fig. 3. Spectrum measured, at point $P 2$, in the horizontal radial direction

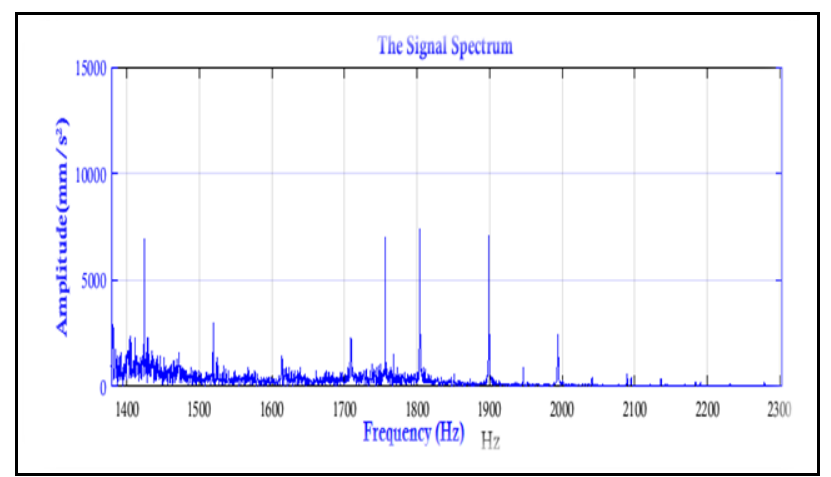

Fig. 4. Spectrum zoomed around $\mathrm{Fn}=1900 \mathrm{~Hz}$.

Published By: 


\section{Improved Diagnosis of Boiler Feed Pumps in a Thermal Power Plant}

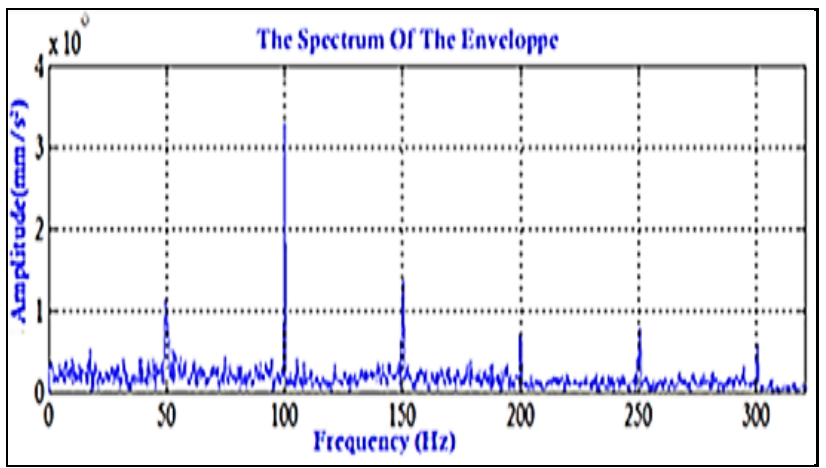

Fig. 5. Spectrum of the envelope measured a round Fn $=1900 \mathrm{~Hz}$.

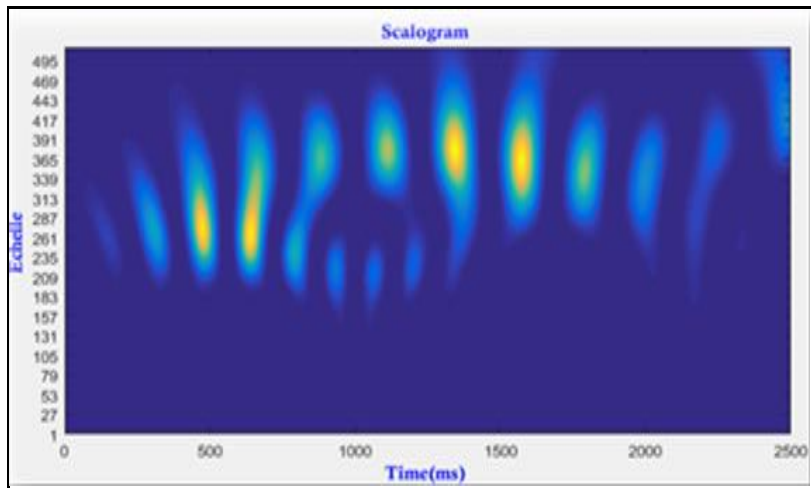

Fig. 6. Scallogram of the signal measured at point $P 2$, in the Horizontal radial direction

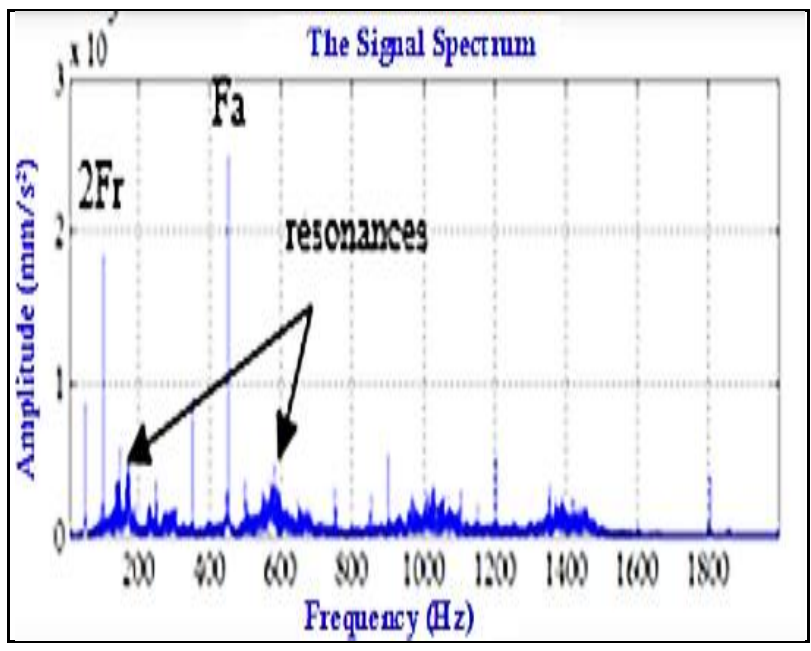

Fig. 7. Spectrum measured, at point $P 4$, in the horizontal radial direction.

\section{CONCLUSION}

The boiler feed pump represents, for the thermal energy plant, the "heart" that beats since it continuously supplies the boiler with the treated water necessary for the production of superheated steam that turns the turbine. Its continuous inspection is therefore necessary.

Vibration analysis is a very effective conditional maintenance technique for the control and diagnosis of rotating machines.

The application of the spectral analysis and the phase analysis to the controlled motor pump revealed the existence of an imbalance in the motor shaft and the existence of a cavitation defect in the pump. In the same way, the analysis of the envelope has shown the existence of a defect in the stator and a dynamic defect of the eccentricity of the rotor.

\section{REFERENCES}

1. H. ELMaati. “ Contribution des techniques avancées de la maintenance à l'optimisation de la production. Application à la Centrale Thermique de Production de l'Energie Electrique “.Thèse, Université Mohammed premier, 2016, Oujda.

2. H. Elmaati, A. Benbouaza, B. Elkihel, and F. Delaunois. (2013, December). "Implmentation of a vibration monitoring system of a steam turbine for optimization of the maintenance". International Journal of Emerging Trends \& Technology in Computer Science, 2(6), pp. 240-245.

3. H. Elmaati, A. Benbouaza, B. Elkihel, and F. Delaunois. (2013, June). "Development of a vibration monitoring system for optimization of the electrical energy production". International Journal on Computer Science and Engineering, 5(6), pp. 240-589.

4. M. E. K. Oumaamar, H. Razik and A. Khezzar, "Experimental in vestigation of stator current signature in defective induction motor " , Proc. IEEE , pp. 3443-3448, 2009.

5. C.K. Sung, H.M. Tai, C.W. Chen. (2000, August). Locating defects of a gear system by the technique of wavelet transform". Mechanism and Machine Theory. 35(8), pp. 1169-1182.

6. Dr.N. Kuppuswamy. (2013, June). "Vibration and cavitation prediction and control of turbine alternator in hydroelectric power plants". Australian Journal of Basic and Applied Sciences. 7(8), pp. 19-28.

7. R. Zarrouk, H. El Maati, M. El Amrani, and H. Santillan-Ortiz. (2017, December). "Diagnostic of a thermal power plant turbo-alternator group", International Journal of Emerging Trends \& Technology in Computer Science. 6(6), pp. 110-114.

8. A. Boulenger and P. Christian. Surveillance des machines par analyse des vibrations, Dunod, France, 2009.

9. M.Feldman. (2011, April). "Hilbert transform in vibration analysis. Mechanical". Systems and Signals Processing. 25(3), pp. 735-802.

10. J. R. Pstack, R. G. Harley, and T. G. Habetler. (2004, October). ' An amplitude modulation detector for fault diagnosis in rolling element bearings". IEEE Trans. Ind. Electron .51(5), pp. 1097-1102.

11. Philippe. "Numerical and experimental methodological approach to aid in the detection and monitoring of vibration of chipping defects of ball bearings," Thesis, University of Reims Champagne Ardenne Faculty of Natural Sciences, December. 2004.

12. S.S. Ajanalkar, Prof. Shrigandhi G. D. (2015, May). "Review on fault identification and diagnosis of gear Pair by experimental vibration analysis". Journal of Emerging Technologies and Innovative Research. 2(5), pp. 1366-137.

13. P. GRANJON. "Contribution has the active compensation of vibration on the electrical machines". Thesis, Institut National Polytechnique of Grenoble, December 2000.

14. A. Medoued, A. Lebaroud and D. Sayad. (2013, January). "Application of Hilbert transform to fault detection in electric machines". Advances in Difference Equations a Springer Open Journal. pp. 1-7.

15. C. CK. (1992, January). "An introduction to wavelets: Wavele analysis and its applications“. First Edition, Academic Press, Vol.1, pp. 266.

16. R. Yan, R. X. Gao, X. Chen. (2014, March). "Wavelets for fault diagnosis of rotary machines: A review with application ". Signal Processing, Vol. 96, Part A, pp.1-15.

17. M. Ayad, Dj. Chikouche, N. Boukezzoula, M. Rezki. (2012, April) "Early damage detection of gear systems through wavelet analysis of vibration signal “. International Journal of Mechanical Engineering and Technology. 3(1), pp. 277-287.

18. M. Ayad, Dj. Chikouche, N. Boukezzoula, M. Rezki. (2014, December). "Search of a robust defect signature in gear systems across adaptive Morlet wavelet of vibration signals “. IET Signal Processing. 8(9), pp. $918-926$.

19. H. ÖZTÜRK, M. SABUNCU, I. YESILYURT. (2008, April).” Early Detection of Pitting Damage in Gears using Mean Frequency of Scalogram". Journal of Vibration and Control. 14(4), pp. 469-484.

20. R. Zarrouk, M. EL Amrani, B. El Kihel. 2016. "V_System : Système d'Acquisition, d'Analyse et de Traitement de Signaux Vibratoires". in Conférence internationale, Les matériaux innovants \& leurs applications, Oujda, Maroc.

21. S. Pejovic, Q.F. Zhang, B. Karney, A. Gajic. 2011. “Analysis of pumpturbine ' $S$ ' Instability and revers water hammer incidents in hydro power systems. " 4 th International Meeting on Cavitation and Dynamic Problems in Hydraulic Machinery and Systems, pp. 1-16. 


\section{AUTHORS PROFILE}

Redouan Zarrouk PhD student research in industrial engineering on the theme maintenance the complex Installations industrials by vibration analysis. $\mathrm{He}$ is presently pursuing his PhD program in Laboratory of Electronic and Systems, Faculty of Sciences University Mohammed I, Oujda, Morocco, on the theme ',

Development of a system acquisition, analysis and processing of vibratory signals dedicated to the controls of rotating machines". .

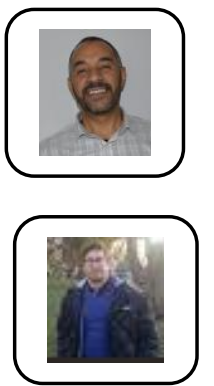

Mostafa EL Amrani professor of Higher Education University Mohammed I, Oujda, Morocco. PhD of University Jussieu Paris 7 France in Non Destructive Testing. He was an engineer of maintenance in CEA Saclay France.

division. He

Hassane Elmaati received his engineer degree in Materials engineering in 1997 at the National School of Mineral Industry (ENIM), Rabat, Morocco. Since 1998 until today, He is an engineer of maintenance in a thermal power plant in Morocco. Chief of technical Department, National School of Applied Sciences University Mohammed I, Oujda, Morocco, on the theme "Optimization of the production by an intelligent maintenance".

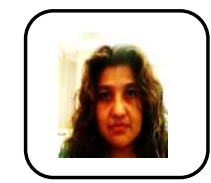

Hortensia Santillan Ortiz professor of Science, Department in Technological University of Mexico, Ecatepec, Estado de México 